\title{
Multiobjective Optimization of Allocated Exchange Portfolio: Model and Solution-A Case Study in Iran
}

\author{
Mostafa Ekhtiari \\ Department of Industrial Management, Management and Accounting, Shahid Beheshti University, Tehran, Iran \\ Correspondence should be addressed to Mostafa Ekhtiari; m_ektiari@yahoo.com
}

Received 21 September 2013; Accepted 13 November 2013; Published 30 January 2014

Academic Editors: X.-L. Luo and Y. Shi

Copyright ( 2014 Mostafa Ekhtiari. This is an open access article distributed under the Creative Commons Attribution License, which permits unrestricted use, distribution, and reproduction in any medium, provided the original work is properly cited.

\begin{abstract}
This paper presents a triobjective model for optimization of allocated exchange portfolio. The objectives of this model are minimizing risk and investment initial cost (by adopting two synchronic policies of buying and selling assets) and maximizing return, to optimize allocated portfolios (APs). In an AP, an investor by considering previous investment experiences and market conditions selects the within portfolio assets. Then, considering proposed model, the assets proportion of AP is optimized for a limited time horizon. In optimizing a multiobjective problem of an AP, risk and return objectives are measured on the basis of standard deviation of assets dairy return and dairy return mean within AP assets, respectively. We present a set of interobjectives trade-offs along with an analysis of Iran Melli bank investment in an exchange AP, using Weighted Global Criterion (WGC) method with assumption $p=1,2$, and $\infty$ to optimize the proposed model. Results of WGC model (in all $p=1,2$ and $\infty$ ) represent that US dollar exchange in comparison with other exchanges, was rather the fewest exchange proportion in Iran Melli bank exchange AP which this is consistent with Iran exchange investment policy of more concentration on other exchanges.
\end{abstract}

\section{Introduction}

Markowitz [1] was the first one who quantified risk in financial management. He presented that finance decisions should be made on the basis of risk and return and finally, he presented efficient frontier in finance decisions. All points on this line were optimal. That is, investor obtains minimum risk and maximum return on a certain level of return and on a certain level of risk, respectively [1]. According to the Markowitz approach, risk and future returns of a portfolio are random variables which are controlled by the following two parameters.

(i) Portfolio return: is measured by dairy return expected value of assets.

(ii) Portfolio risk: is measured by standard deviation of assets dairy return (see, e.g., [2-4]).

Markowitz mean-variance model was a quadratic planning model by some lateral constraints [2]. Roy [5] presented an approach to determine the optimum level of risk and return. $\mathrm{He}$ considered the implications of minimizing the upper bound of the chance of a dread event, when the information available about the joint probability distribution of future occurrences is confined to the first and second moments. Sharpe [6] established portfolio scientific management, by his researches. He introduced $\beta$ sensitivity coefficient, which indicates changes of stock return rate as compared with changes of market return rate that is called relative risk. Some of the latest works concerning portfolio selection problems are Vafaei Jahan and Akbarzadeh-T [7], Amiri et al. [8], Zhang et al. [9], and Li et al. [10].

Importance of finance risk management significantly developed from the 1970s. As, in that decade, fall of exchange rate constancy system and oil birate crisis were seen. While a number of finance bankrupts such as the fall of international stock market in 1987, Mexican crisis in 1995, Asian crisis in 1997, and Orange-County and Barings bank collapses in 1994, the attitude to this tendency becomes strong. These cases, all showed inability of available risk management tools, finance system elegance, and consequences of possible finance crisis [11].

First let us have some economic definition of risk. Investment dictionary defines risk as investment potential loss which is computable [12]. Besides introducing risk as 
a numerical index, Markowitz also defines it as multicyclical standard deviation of a variable. For example, risk of exchange rate during the years 2000 to 2008 is standard deviation of exchange rate in these years [1].

Generally, economic investors consider two different kinds of portfolio investment decisions: a number of them, using multiobjective economic models and analyzing them, try to select and allocate the best composition of assets for investment in a portfolio (see, e.g., $[13,14]$ ). In this case, investor may have an optimal composition of allocated assets on which investment may not be possible because of market conditions. For example, now foreign exchange investment policy of Iran offers less concentration on exchanges like American dollar. Another group of investors select portfolio assets, using previous experiences and market conditions and then by the use of multiobjective economic models and heuristic methods, optimize allocated portfolio (AP) for a limited time horizon in the future. Furthermore, in this kind of investment, portfolio management decisions will be often repeated at the end of the specified time horizon (see, e.g., $[15,16])$. For instance, banks are of economic agencies, which considering past exchange trade-off extent, use AP optimization in a finance term for future investment in an exchange portfolio. From AP optimizing advantages are making opportunity for increasing assets (buy policy) or decreasing existent assets (sell policy).

Our purpose in this paper will be the latter kind of investment. The point which should be considered by investor in selecting the assets within an AP is the existence of balance in assets two by two overlapping. So that if all of AP assets two by two overlapping are positive in a moment of time, it will mean that there is a high probability for obtaining investment, more profit, and more return as well. But if all of AP assets two by two overlapping are negative in a moment of time, it will mean that there is a low probability for obtaining investment, more profit, and more return as well. So, in order to obtain proper tradeoffs of risk and return, in the balance case, we have to have both negative and positive overlapping for two by two of assets in an AP.

Generally, the process of an AP optimization is as follows: first, the investor introduces a certain level of his/her assets. Then, using past information, the analyst draws out required statistic indices and performs optimization process by offering a multiobjective model and will provide a set of objectives of different optimal levels for the investor. Finally, considering limited time horizon in future, the investor will make the last decision about increase or decrease of within AP assets level.

Having various objectives is helpful to make better decisions in the future. Most of investors are interested in having information like investment cost, risk, and return to make better decisions. According to economic theories, everyone can have different compositions of risk and return levels on the basis of which risk and return trade-offs make no difference for us. Pareto frontier will be drawn by connecting these points together. Of course, one does not practically draw these graphs to make decision and performs the decision making process rather by an ocular viewpoint based on recognition of ones own specifics.
When investors accept higher level of risk, they will obtain more return which is called risk premium. Because of condition changes, various people accept different levels of risk which is more on the basis of their received information from market as their psychological and behavioral specifics at the time of decision making. On the other hand, all risks could not be eliminated due to the fact of considering the straight relation between risk and return; the opportunities will be eliminated too. So we have to pay attention to risk and return simultaneously. Obviously, acceptance of higher risk will be accompanied by more return.

On the other hand, one of the most important goals which investors always want to decrease is investment initial cost. People always want an investment in an economic field by higher capital return and lower risk and investment initial cost. Of course, it is an idealistic approach, it should be added that investment in an AP may not be always associated with buying new assets and investment may even begin by selling present assets. Anyway, it is considerable for investor to inform about assets buying or selling extent by regard of return and risk objectives. So, in this paper, considering bank investment on an exchange AP, we will model investment initial cost objective on the basis of an AP's specifics as well as risk and return objectives.

The risk we consider in this paper is exchange rate risk which is caused by change in exchange rate. All companies which are out of political borders are dealing with countries having different currencies that are exposed to exchange rate risk. Exchange rate risk influences the organization ability to payback the foreign loans. Also may cause the organization not to be able to perform its commitments for forward purchasing of goods from foreign markets. In the other word, changes of exchange rate influence goods and capital market and may even have destructive effects. Finance institute working in exchange market should consult for sufficient coverage against future fluctuations of exchange rate. It is clear that banks and finance institutes will sustain great losses, if they do not consider the optimal composition of an exchange portfolio and each exchange's state in the international markets. So computation of exchange rate risk by banks is effective in decreasing the loss caused by exchange rate fluctuations.

Iran has experienced vast changes of exchange rate and its destructive effects during 20 years. Most of industrial plans in Iran which were profitable on the basis of the time exchange rate at the time of startup and economic study became bankrupt after decrease of Rials (formal currency of Iran) value because of dependence on imported raw material and companies went bankrupt as well. Of these industries we can name matting industry which became bankrupt after exchange rate changed from 1750 Rials to 8000 Rials. Also, recently most of investors, importers, and banks have sustained losses because of extreme increase of Euro price and fluctuations of other exchanges. Thus, government tries to compensate this loss by giving loan to investors through withdrawal of country exchange reserve account. So it seems necessary for Iranian investors to know risk level for foreign investment, so that knowing will prevent disadvantages caused by irrelevant discount of country income. Second 
it seems that Iranian investors, beside the return objective, do not consider risk objective so much or they do not pay enough attention to it as an important objective for investment. Whereas, return and risk objectives should be assessed together. And the third, consumption of irrelevant costs, when the investor knows nothing about expected risk and return level of his/her investment, this influences future decisions. So it is always favored for investors to find a solution to decrease investment initial cost beside decrease of risk and increase of future return.

Our main motivations for presenting this paper is lack of a monorate exchange regime in Iran before 2002 and the traditional viewpoint of Iranian investors which has often failed. In this paper, using Markowitz mean-variance model and adding a objective function of investment cost for an exchange AP which include five major exchanges present in foreign investment portfolio of Iran Melli bank, we optimize triobjective problem by the Weighted Global Criterion (WGC) method and consider interobjectives tradeoffs of investment risk, return, and initial cost by making consider inter-objectives trade-offs of investment risk, return, and initial cost by making changes in preference weights of the objectives. After evaluation of results based on the norms $p=1,2, \infty$, is presented a proper procedure to investor (bank), for making decision about investment in a one year time horizon.

The paper continues as follows: in Section 2, a triobjective model by objectives of investment risk, return, and initial cost on the basis of Markowitz mean-variance model is offered. WGC method along with a review of its literature for solution of our proposal model is presented in Section 2. Also in order to determine maximum expected loss of an AP in a future time horizon, the Value-at-Risk (VaR) method is introduced in this section. Next, in Section 3, we illustrate our proposal model on an exchange AP which includes five major exchanges present in Iran Melli bank and analyze obtained results based on the norms $p=1,2$, and $\infty$ and finally, Section 4 presents conclusions and final remarks.

\section{Problem Modelin}

Markowitz [1] mean-variance model obtains optimal risk value for an explicit level of return by minimizing variance of total within portfolio assets.

Here, we model our proposal triobjective model by making a change in Markowitz mean-variance model, where $i$ (for $i=1,2, \ldots, m$ ) is number of existent assets in AP, $x_{i}$ (for $i=1,2, \ldots, m)$ is the decision variable of asset proportion $i$ th (for $i=1,2, \ldots, m$ ) in optimal AP, and $R_{i}$ is daily return random variable of asset $i$ th (for $i=1,2, \ldots, m$ ) with normally distributed that is computed as follows:

$$
R_{i t}=\ln \left(\frac{p_{i t}}{p_{i(t-1)}}\right), \quad i=1,2, \ldots, m,
$$

where $p_{i t}$ is price of asset $i$ th (for $i=1,2, \ldots, m$ ) in day $t$ th of understudy term and $R_{i t}$ is logarithmic return of asset $i$ th (for $i=1,2, \ldots, m)$ in day $t$ th of understudy term. $E\left(R_{i}\right)$ is daily return mean of asset $i$ th (for $i=1,2, \ldots, m$ ) and $\operatorname{Var}\left(R_{i}\right)$ is daily return variance of asset $i$ th (for $i=1,2, \ldots, m$ ). Also, $\sigma_{\mathrm{AP}}^{2}=\sum_{i=1}^{m} \operatorname{Var}\left(R_{i} x_{i}\right)$ and $R_{\mathrm{AP}}=\sum_{i=1}^{m} E\left(R_{i} x_{i}\right)$ are return variance and mean of all AP assets, respectively.

In an AP, if $M_{i \text { (existent) }}, N_{i \text { (existent) }}$, and $p_{i}$ are present value of existent asset $i$ th (for $i=1,2, \ldots, m$ ), number of existent asset $i$ th (for $i=1,2, \ldots, m$ ), and price of asset $i$ th (for $i=$ $1,2, \ldots, m)$ in the last day of understudy term, respectively, then

$$
N_{i(\text { existent })}=\frac{M_{i(\text { existent })}}{p_{i}}, \quad i=1,2, \ldots, m .
$$

Also if $x_{i \text { (existent) }}$ is existent proportion of asset $i$ th (for $i=$ $1,2, \ldots, m)$ of an AP in the last day of understudy term, then

$$
x_{i(\text { existent })}=\frac{N_{i(\text { existent })}}{\sum_{i=1}^{m} N_{i(\text { existent })}}, \quad i=1,2, \ldots, m
$$

where finally, $E\left(R_{i}\right) \times x_{i \text { (existent) }}$ is minimum aspiration level of return belonging to asset $i$ th (for $i=1,2, \ldots, m$ ) in an AP in the last day of understudy term and $\sum_{i=1}^{5} E\left(R_{i}\right) \times x_{i \text { (existent) }}$ is minimum aspiration level of same AP in the last day of understudy term for all assets as well.

In this section we propose a new objective for Markowitz model which is called investment initial cost. Purpose of this objective is to minimize investment cost. This minimum investment initial cost means minimizing new assets buying cost but includes AP assets selling subject as well. Our purpose is decrease of new assets buying cost that may sometimes cause income earning from selling existent assets. Thus, in this paper we consider final results obtained from within AP investment initial cost objective by two variables $\mathrm{C}_{\mathrm{AP}}^{-}$(income variable caused by selling $\mathrm{AP}$ existent assets) and $\mathrm{C}_{\mathrm{AP}}^{+}$(cost variable of new assets buying).

Investor initiates the investment on the basis of last price present for each asset sole. So as the investor wants to know risk and return level of his/her investment before investment on an AP in a new finance term, he/she could be presented a set of tradeoffs between investment risk, return, and initial cost objectives. Because each asset price in understudy term changes a little, so we use least period demand method to predict future price for performing assets sell or buy policy, so that assets future price in beginning days of time horizon is predicted to be equal to their present price. So in general we can show AP cost objective function as a linear combination of the number of assets which should be bought $\left(y_{i}\right)$ and the price of each asset in the last understudy day $\left(p_{i}\right)$. Results can be seen as

$$
C_{\mathrm{AP}}=\sum_{i=1}^{m} p_{i} y_{i}
$$

Considering situation of existent assets, our purpose is buying new assets for future. Thus, $y_{i 1}$ is total number of asset $i$ th (for $i=1,2, \ldots, m$ ) which we have at present, $y_{i 2}$ is total number of asset $i$ th (for $i=1,2, \ldots, m$ ) which we will have at the future and $y_{i}$ is number of asset $i$ th (for $i=1,2, \ldots, m$ ) 
which we must buy, regardless of situation of existent assets. So (4) can be also written as

$$
C_{\mathrm{AP}}=\sum_{i=1}^{m} p_{i}\left(y_{i 2}-y_{i 1}\right) .
$$

If $y=\sum_{i=1}^{m} N_{i(\text { existent })}$ is the total number of existent assets in $\mathrm{AP}$, then

$$
y_{i 2}=y x_{i}, \quad i=1,2, \ldots, m .
$$

Considering (5) and (6), we have

$$
C_{\mathrm{AP}}=\sum_{i=1}^{m} p_{i}\left(y x_{i}-y_{i 1}\right) .
$$

The following should be noted about (7).

(i) If $\sum_{i=1}^{m} p_{i} y x_{i}>\sum_{i=1}^{m} p_{i} y_{i 1}$, then $C_{\mathrm{AP}}^{+}=C_{\mathrm{AP}}>0$; that is, buy policy is offered for investment and optimal value of objective $C_{\mathrm{AP}}$ is considered as minimum cost of new assets buying.

(ii) If $\sum_{i=1}^{m} p_{i} y x_{i}<\sum_{i=1}^{m} p_{i} y_{i 1}$, then $C_{\mathrm{AP}}^{-}=C_{\mathrm{AP}}<0$; that is, sell policy is offered for investment and $\left|C_{\mathrm{AP}}\right|$ is considered as maximum income obtained of selling existent assets.

(iii) If $y x_{i}=y_{i 1}$, then $C_{\mathrm{AP}}=0$ (for $\left.i=1,2, \ldots, m\right)$; that is, from cost point of view, investment would be proper by existent assets.

It should be added that if we consider assets buy policy, $C_{\mathrm{AP}}$ is buy initial cost objective and it is important that we minimize it. Also, if we consider assets sell policy, $C_{\mathrm{AP}}$ is income objective obtained of selling the assets and it is important that we maximize it. So, as presupposition, we consider $C_{\mathrm{AP}}$ as investment initial cost objective by policies of selling or buying the assets. So our proposed triobjective model is problem (P1):

$$
\begin{aligned}
\text { (P1): Opt } & \left(\sigma_{\mathrm{AP}}^{2}, R_{\mathrm{AP}}, C_{\mathrm{AP}}\right) \\
\text { s.t. } & \sum_{i=1}^{m} x_{i}=1, \\
& x_{i} \geq 0, \quad i=1,2, \ldots, m .
\end{aligned}
$$

Problem (P1) is a constrained triobjective decision model that incorporates tradeoffs between competing objectives of risk, return, and cost for investment. Equation (8) is the objective vector to be optimized with respect to the fact that investment risk of existent assets in AP is wished to be minimized, return obtained from investment on $\mathrm{AP}$ is wished to be maximized, and initial cost of investment on AP assets is wished to be minimized. Equation (9) is the same constraint of variance-covariance primary model, which is presented here. This constraint implies that sum of total proportions of existent assets in AP will always be equal to one. Also, (10) guarantees which each asset proportion in optimal AP be non-negative.
In (P1), minimizing AP daily return variance is used to minimize risk objective. Besides, because a portfolio's return is measured by assets daily return expected value, so in (P1), return objective will be maximized by linear combination of AP assets daily return mean [2].

It should be considered that solving (P1) does not yield only one optimal solution and yields a set of optimal nondominated solutions which are on Pareto frontier, instead. To describe the concept of optimality in which we are interested, we will introduce next a few definitions.

Definition 1. Given two vectors $x, y \in R^{k}$, one may say that $x \geq y$ if $x_{i} \geq y_{i}$ for $i=1,2, \ldots, k$, and that $x$ dominates $y$ (denoted by $x>y$ ) if $x \geq y$ and $x \neq y$.

Consider a biobjective optimization problem with three different solutions 1,2 , and 3 , where solutions 1 and 2 are displayed with vectors $x$ and $y$, respectively. The ideal solution is displayed with 4 . Function $F_{1}$ needs to be maximized and $F_{2}$ needs to be minimized (see Figure 1).

Comparing solutions 1 and 2, solution 1 is better than solution 2 in terms of both objective functions. So it can be said that $x$ dominates $y$ and we display this with $x>y$.

Definition 2. One may say that a vector of decision variables $x \in S \subset R^{n}$ ( $S$ is the feasible space) is nondominated with respect to $S$, if there does not exist another $x^{\prime} \in S$ such that $f(x)>f\left(x^{\prime}\right)$.

In Figure 1, if solutions 1 and 3 are displayed with vectors $x$ and $z$, respectively, then comparing 1 and 3 , we see 3 is better than 1 in terms of $F_{1}$, whereas 1 is better than 3 in terms of $F_{2}$, where $x \nsucc z$ and $z \nsucc x$. So in here, vectors $x$ and $z$ are nondominated with respect to each other.

Definition 3. One may say that a vector of decision variable $x^{*} \in S \subset R^{n}$ is Pareto optimal, if it is nondominated with respect to $S$.

Let suppose that $x^{*} \notin S$ be a solution such as 4 . In this state, the above assumption is violated because $x^{*}$ is a dominated solution which dominates all other solutions. So $x^{*}$ can be a solution such as 1 or 3 which are nondominated.

Definition 4. The Pareto optimal set $P^{*}$ is defined by

$$
P^{*}=\{x \in F \mid x \text { is Pareto optimal }\} .
$$

Definition 5. The Pareto Frontier $\mathrm{PF}^{*}$ is defined by

$$
\mathrm{PF}^{*}=\left\{f(x) \in R^{k} \mid x \in P^{*}\right\} .
$$

2.1. The WGC Method. Of the proper assessment methods, when investor information are unavailable, are methods related to $l_{p}$-norm family, so that by change of objectives importance weight, there is no need for investor's primary information. In such methods, investor will not be disturbed but analyst should be able to consider assumptions about investor's preferences. For incorporating weights in GC, we use approach (13) (for more details, see [17]): 


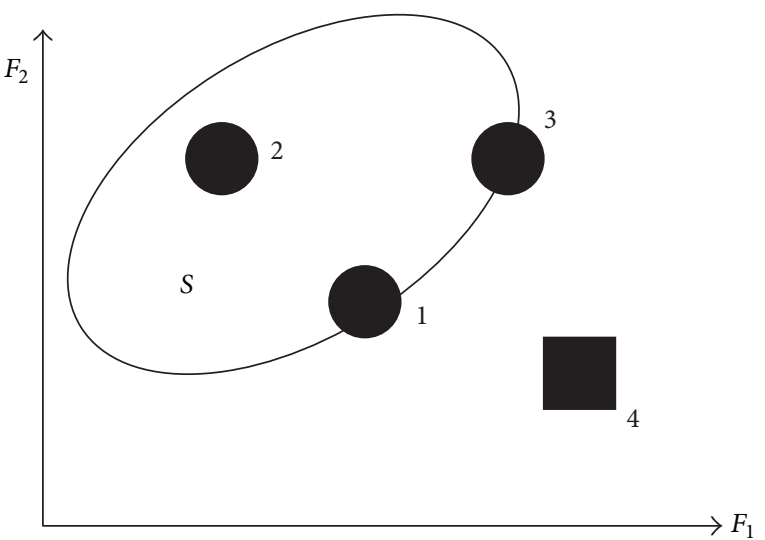

FIGURE 1: Illustration of feasible space and ideal solution for a biobjective problem with objectives maximize and minimize.

$$
l_{p} \text {-norm }=\left\{\sum_{k=1}^{K} w_{k}\left(\frac{f_{k}\left(x^{* k}\right)-f_{k}(x)}{f_{k}\left(x^{* k}\right)-f_{k}\left(x_{*}^{k}\right)}\right)^{p}\right\}^{1 / p},
$$

where $x=\left(x_{1}, x_{2}, \ldots, x_{m}\right)$. The formulation in (13) is called standard weighted global criterion formulation. Minimizing (13) is sufficient for Pareto optimality as long as $w_{k}>0$ (for $k=1,2, \ldots, K)[17]$.

For each Pareto optimal point $x_{p}$, there exists a vector $w=\left(w_{1}, w_{2}, \ldots, w_{K}\right)$ and a scalar $p$, such that $x_{p}$ is a solution to (13). The value of $p$ determines to what extent a method is able to capture all of the Pareto optimal points (with change in vector $w$ ), even when the feasible space may be nonconvex. With (13), using higher values for $p$ increases the effectiveness of the method in providing the complete Pareto optimal set [18]. However, using a higher value for $p$ enables one to better capture all Pareto optimal points (with change in $w$ ). The weighted min-max formulation, which is a special case of the WGC approach with $p=\infty$, has the following format $([19,20]$ and $[21])$ :

$$
\begin{array}{ll}
\text { (P2): } \min & y \\
\text { s.t. } & y \geq w_{k}\left(\frac{f_{k}\left(x^{* k}\right)-f_{k}(x)}{f_{k}\left(x^{* k}\right)-f_{k}\left(x_{*}^{k}\right)}\right), \\
& k=1,2, \ldots, K \\
& g_{l}(x) \leq b_{l}, \quad l=1,2, \ldots, L \\
& y \geq 0 .
\end{array}
$$

Using (P2) can provide the complete Pareto optimal set, so that it provides a necessary condition for Pareto optimality [19].

In set of WGC methods, the goal is to minimize the existence objective functions deviation from a multiobjective model related to an ideal solution. Yu [20] called the ideal point $x^{*}$ as a utopia point. We optimize each objective function separately to reach utopia point and for $x \in S$. It means that in this state, ideal solution is obtained from solving $K$ monoobjective problems as follows:

$$
\begin{array}{cl}
\text { (P3): optimize } & f_{k}(x), \quad k=1,2, \ldots, K \\
\text { s.t. } & g_{l}(x) \leq 0, \quad l=1,2, \ldots, L
\end{array}
$$

where utopia point coordinates are $\left\{f_{1}\left(x^{* 1}\right), f_{2}\left(x^{* 2}\right)\right.$, $\left.\ldots, f_{K}\left(x^{* K}\right)\right\}$ and $x^{* K}$ optimizes $k$ th objective. Meanwhile, $x_{*}^{k}$ is vector of nadir solution. So we can minimize $K$ problem for each objective function in solution space (if objectives maximizing is supposed) to reach nadir solution.

Considering approach (13), if all $f_{k}(x)$ are of maximizing type, then $w_{k}$ shows weight of objective $k$ th (for $k=$ $1,2, \ldots, K)$ with $0<w_{k}<1$. Also, $1 \leq p \leq \infty$ shows indicating parameter of $l_{p}$-norm family. Value $p$ indicates emphasis degree on present deviations, so that the bigger this value, is the more emphasis on biggest deviation will be. If $p=\infty$, it means that the biggest present deviation is considered for optimizing. Usually values $p=1,2$, and $\infty$ are used in computations. Anyway, value $p$ may depend on investors mental criteria. Given values $w_{k}$, solution obtained from minimizing the approach (13) is known as a consistent solution.

So far, WGC approach has been widely applied in engineering sciences (see, e.g., [22]). There is no significant study performed about application WGC method to solve optimization portfolio problems. On the other hand, considering WGC method ability to represent Pareto optimal set, it seems that there are no researches performed about using this method for optimizing the APs so far. So another part of our motivations to present this paper is WGC method's effectiveness in representing a complete set of Pareto optimal points in optimizing portfolio problems.

Using approach (13), we formulate (P1) in the form of (P4) based on the WGC method:

$$
\begin{aligned}
\text { (P4): } \min & \left\{w_{1}\left(\frac{Z^{* 1}+F_{1}}{Z^{* 1}-Z_{*}^{1}}\right)^{p}\right. \\
& \left.+w_{2}\left(\frac{Z^{* 2}-F_{2}}{Z^{* 2}-Z_{*}^{2}}\right)^{p}+w_{3}\left(\frac{Z^{* 3}+F_{3}}{Z^{* 3}-Z_{*}^{3}}\right)^{p}\right\}^{1 / p} \\
\text { s.t. } & \sum_{i=1}^{m} x_{i}=1, \\
& x_{i} \geq 0, \quad i=1,2, \ldots, m,
\end{aligned}
$$

where $w_{k}$ is relative importance weight of objective $k$ th (for $k=1,2,3)$, where $0<w_{k}<1$ and $w_{1}+w_{2}+w_{3}=$ 1. Also, $Z^{* k}$ (for $k=1,2,3$ ) is utopia value of objective function $k$ th (here, maximum value of objective function $k$ th is in solution space), $Z_{*}^{k}$ (for $k=1,2,3$ ) is nadir value of objective function $k$ th (here, minimum value of objective function $k$ th is in solution space), and $F_{k}$ (for $k=1,2,3$ ) is the $k$ th objective function. $F_{1}$ is the risk objective function, $F_{2}$ is return objective function and $F_{3}$ is the initial cost objective function. The tradeoffs between objectives is done by changing $w_{k}$ values. $p$ is parameter of final utility function for which values 1,2 , and $\infty$ are supposed in this paper. Considering ( $\mathrm{P} 4)$, interobjectives trade-offs general process is as follows:, first we suppose that investor wants importance 
weight of risk objective be 0.9. So using WGC method, analyst obtains a set of tradeoffs between return and cost objectives by assuming importance weight of risk objective to be constant; he/she decreases importance weight of risk objective by a descending manner and tradeoffs between investment return and cost objectives will be reregistered.

2.2. The VaR Method. One of the most popular techniques to determine maximum expected loss of an asset or portfolio in a future time horizon and with a given explicit confidence level (VaR definition) is the VaR method. Dowd et al. [23] for computation of the VaR associated with normally distributed log-returns in a long-term applied the following:

$$
\begin{aligned}
\operatorname{VaR}_{\mathrm{AP}}(T) & =M-M_{\mathrm{cl}} \\
& =M-\exp \left(R_{\mathrm{AP}} T+\alpha_{\mathrm{cl}} \sigma_{\mathrm{AP}} \sqrt{T}+\ln (M)\right) .
\end{aligned}
$$

Generally considering (17), $\operatorname{VaR}_{\mathrm{AP}}(T)$ is $\mathrm{VaR}$ of total AP for time horizon understudy in the future $T$ days and $M$ is total present value of AP assets. So, in here, we have

$$
M=\sum_{i=1}^{m} M_{i(\text { existent })}
$$

Also, $\sigma_{\mathrm{AP}}$ is standard deviation of $\mathrm{AP}$ and the VaR confidence level is $\mathrm{cl}$ and we consider $\mathrm{VaR}$ over a horizon of $T$ days. $M_{\mathrm{cl}}$ is the $(1-\mathrm{cl}$ ) percentile (or critical percentile) of the terminal value of the portfolio after a holding period of $T$ days and $\alpha_{\mathrm{cl}}$ is the standard normal variate associated with our chosen confidence level (e.g., so $\alpha_{\mathrm{cl}}=-1.645$, if we have a 95\% confidence level; see, e.g., [24]).

\section{Case Study}

In order to perform tradeoffs or future risk coverage or diversify exchange reserves, Iranian banks perform exchange buying and selling. One of these banks is Bank Melli Iran, which officially started its banking operation in 1928. The initial capital of this Iranian bank was about 20000000 Rials. Nowadays, enjoying 85 years of experience and about 3200 branches, this bank, as an important Iran economic and finance agency, has an important role in proving country's enormous economic goals by absorbing community's wandering capitals and using them for production. Also, from international viewpoint, Bank Melli Iran with 16 active branches enjoys distinguished position in rendering banking services. The most important actions of Bank Melli Iran in international field include opening various deposit accounts; performing currency drafts affairs; issuing currency underwriting; opening, confirming, covering, and conforming documentary credits; and so forth.

Here, we consider an exchange AP including five main exchanges in Iran Melli bank exchange investment portfolio. These five exchanges include US dollar, England pound, Switzerland frank, Euro, and Japan 100 yen. The point which investor Melli bank considers after yielding the results is the proportion of US dollars. Right now Iran foreign exchange investment policy necessitates less concentration on this exchange. Understudy data include these five exchanges daily rate from 25 March 2002 to 19 March 2012. This studied term is short because of lack of exchange monorate regime in Iran exchange policy in years before 2002 .

Here, $x_{1}, x_{2}, x_{3}, x_{4}$ and $x_{5}$ are exchanges proportion of US dollar, England pound, Switzerland frank, Euro, and Japan 100 yen of Melli bank total exchange AP, respectively. Table 1 illustrates statistic indices obtained from these five exchanges daily rates during the study term.

Also, variance-covariance matrix obtained from these five exchanges daily return during the study term is according to Table 2.

Present value of Iran Melli bank exchange AP and minimum aspiration level of AP return in the last day of study term (19 March 2012) along with other information are presented in Table 3.

By considering information of Table 3, we can rewrite (P4) in the form

$$
\begin{aligned}
& \left.\begin{array}{rl}
\text { (P5): } \min \quad & w_{1}\left(\begin{array}{c}
Z^{* 1}+\left(\begin{array}{c}
0.005978413 x_{1}^{2}+5.0975 E-05 x_{2}^{2}+0.006777075 x_{3}^{2}+2.82209 E-05 x_{4}^{2}+3.47045 E-05 x_{5}^{2}-5.50364 E \\
-06 x_{1} x_{2}+6.66602 E-06 x_{1} x_{3}+4.66114 E-06 x_{1} x_{4}+6.73259 E-06 x_{1} x_{5}+3.12959 E-05 x_{2} x_{3}+2.75018 E \\
\left.-05 x_{2} x_{4}+1.15607 E-05 x_{2} x_{5}+5.39984 E-05 x_{3} x_{4}+3.15243 E-05 x_{3} x_{5}+1.93833 E-05 x_{4} x_{5}\right)
\end{array}\right. \\
Z^{* 1}-Z_{*}^{1}
\end{array}\right)^{p} \\
& +w_{2}\left(\frac{Z^{* 2}-\left(8.49735 E-05 x_{1}+0.000272112 x_{2}+0.000314821 x_{3}+0.000349021 x_{4}+0.000170238 x_{5}\right)}{Z^{* 2}-Z_{*}^{2}}\right)^{p} \\
+ & w_{3}\left(\frac{\left.\begin{array}{c}
Z^{* 3}+\left(8904\left(341581517 x_{1}-1909254\right)+17934\left(341581517 x_{2}-36913126\right)+8837\left(341581517 x_{3}-18897816\right)\right. \\
\left.+14111\left(341581517 x_{4}-278506130\right)+9150\left(341581517 x_{5}-5355191\right)\right)
\end{array}\right)^{p}}{Z^{* 3}-Z_{*}^{3}}\right.
\end{array}\right)^{p} \\
& \text { s.t. } \quad \sum_{i=1}^{m} x_{i}=1, \\
& x_{i} \geq 0, \quad i=1,2, \ldots, m \text {. }
\end{aligned}
$$


After simplifying and normalizing constraint coefficients related to cost objective (by dividing above constraint coefficients in the biggest mentioned constraint coefficient), we can rewrite (P5) in the form $\begin{aligned} \text { (P6): } \min \quad & w_{1}\left(\begin{array}{c}\begin{array}{c}Z^{* 1}+\left(\begin{array}{c}0.005978413 x_{1}^{2}+5.0975 E-05 x_{2}^{2}+0.006777075 x_{3}^{2}+2.82209 E-05 x_{4}^{2}+3.47045 E-05 x_{5}^{2}-5.50364 E \\ -06 x_{1} x_{2}+6.66602 E-06 x_{1} x_{3}+4.66114 E-06 x_{1} x_{4}+6.73259 E-06 x_{1} x_{5}+3.12959 E-05 x_{2} x_{3}+2.75018 E \\ -05 x_{2} x_{4}+1.15607 E-05 x_{2} x_{5}+5.39984 E-05 x_{3} x_{4}+3.15243 E-05 x_{3} x_{5}+1.93833 E-05 x_{4} x_{5}\end{array}\right) \\ Z^{* 1}-Z_{*}^{1}\end{array}\end{array}\right)^{p} \\ & +w_{2}\left(\frac{Z^{* 2}-\left(8.49735 E-05 x_{1}+0.000272112 x_{2}+0.000314821 x_{3}+0.000349021 x_{4}+0.000170238 x_{5}\right)}{Z^{* 2}-Z_{*}^{2}}\right)^{p} \\ & +w_{3}\left(\frac{Z^{* 3}+\left(0.496487119 x_{1}+x_{2}+0.492751199 x_{3}+0.786829486 x_{4}+0.510204082 x_{5}-0.787636419\right)}{Z^{* 3}-Z_{*}^{3}}\right)^{p}\end{aligned}$

s.t. $\quad \sum_{i=1}^{m} x_{i}=1$,

$x_{i} \geq 0, \quad i=1,2, \ldots, m$,
TABLE 1: Illustration of statistic indices drawn out of daily rates of five exchanges dollar, pound, frank, Euro, and 100 yen from 25 March 2002 to 19 March 2012.

\begin{tabular}{lcc}
\hline Exchange $($ for $i=1,2, \ldots, m)$ & $E\left(R_{i}\right)$ & $\operatorname{Var}\left(R_{i}\right)$ \\
\hline USA dollar & 0.000084973 & 0.005978413 \\
England pound & 0.000272112 & 0.000050975 \\
Switzerland frank & 0.000314821 & 0.006777075 \\
Euro & 0.000349021 & 0.000028221 \\
Japan 100 yen & 0.000170238 & 0.000034704 \\
\hline
\end{tabular}

where the utopia and nadir values of each objective function are according to Table 4.

Considering Table 4, in the best condition, third objective function is of $C_{\mathrm{AP}}^{-}$variable kind and offers assets selling policy, where normalized income is equal to 0.2948852 unit. Also, and in the worst conditions, it is of $C_{\mathrm{AP}}^{+}$variable kind and offers assets buying policy, where normalized cost value (disregard to its mark) is equal to 0.2123636 unit. So considering (P6) and information of Table 4, we have

$$
\begin{aligned}
&(\mathrm{P} 7): \min w_{1}\left(\begin{array}{r}
-0.0000182639+\left(\begin{array}{c}
0.05978413 x_{1}^{2}+5.0975 E-05 x_{2}^{2}+0.006777075 x_{3}^{2}+2.82209 E-05 x_{4}^{2} \\
+3.47045 E-05 x_{5}^{2}-5.50364 E-06 x_{1} x_{2}+6.66602 E-06 x_{1} x_{3}+4.66114 E-06 x_{1} x_{4} \\
+6.73259 E-06 x_{1} x_{5}+3.12959 E-05 x_{2} x_{3}+2.75018 E-05 x_{2} x_{4}+1.15607 E \\
\left.-05 x_{2} x_{5}+5.39984 E-05 x_{3} x_{4}+3.15243 E-05 x_{3} x_{5}+1.93833 E-05 x_{4} x_{5}\right)
\end{array}\right. \\
-0.0000182639+0.006777075
\end{array}\right)^{p} \\
&++w_{2}\left(\frac{0.000349021-\left(8.49735 E-05 x_{1}+0.000272112 x_{2}+0.000314821 x_{3}+0.000349021 x_{4}+0.000170238 x_{5}\right)}{0.000349021-0.0000849735}\right)^{p} \\
&+w_{3}\left(\frac{0.2948852+\left(0.496487119 x_{1}+x_{2}+0.492751199 x_{3}+0.786829486 x_{4}+0.510204082 x_{5}-0.787636419\right)}{0.2948852+0.2123636}\right)^{p}
\end{aligned}
$$

$$
\begin{array}{ll}
\text { s.t. } & \sum_{i=1}^{m} x_{i}=1, \\
& x_{i} \geq 0, \quad i=1,2, \ldots, m .
\end{array}
$$

To optimize (P7), we first suppose $p=1$ and optimize the (P7) by changing objectives importance weight. To solve (P7), objectives are given various weights, in 99 iterations $(9,11$-fold set of iterations). All obtained results from solving (P7) are presented in Table 8 (in the Appendix (optimal value of third objective function is considered in the form of $-F_{3}$, in all figures and tables of the appendix for this paper. The positive values and values which are specified by negative mark (disregard to their mark) are considered as incomes and buying costs, resp.)) by software Lingo 11.0. In Table 8, 
TABLE 2: Daily return variance-covariance matrix of five exchanges: dollar, pound, frank, Euro, and 100 yen from 25 March 2002 to 19 March 2012.

\begin{tabular}{|c|c|c|c|c|c|}
\hline Exchange & USA dollar & England pound & Switzerland Frank & Euro & Japan 100 yen \\
\hline USA dollar & 0.00597841295 & -0.00000275182 & 0.00000333301 & 0.00000233057 & 0.00000336630 \\
\hline England pound & & 0.00005097503 & 0.00001564795 & 0.00001375091 & 0.00000578037 \\
\hline Switzerland frank & & & 0.00677707505 & 0.00002699918 & 0.00001576213 \\
\hline Euro & & & & 0.00002822086 & 0.00000969165 \\
\hline Japan 100 yen & & & & & 0.00003470445 \\
\hline
\end{tabular}

TABle 3: Present value, price, number, existent proportion, daily return mean, and minimum aspiration level of return specifics of five exchanges: USA dollar, England pound, Switzerland frank, Euro, and Japan 100 yen in Melli bank exchange AP in 19 March 2012.

\begin{tabular}{lcccccc}
\hline Exchange & $M_{i \text { (existent) }}$ & $p_{i}$ & $N_{i \text { (existent) }}$ & $x_{i \text { (existent) }}$ & $E\left(R_{i}\right)$ & $E\left(R_{i}\right) \times x_{i(\text { existent })}$ \\
\hline USA dollar & 17000000000 & 8904 & 1909254 & 0.005589454 & 0.000084973 & 0.000000475 \\
England pound & 662000000000 & 17934 & 36913126 & 0.108065349 & 0.000272112 & 0.000029406 \\
Switzerland frank & 167000000000 & 8837 & 18897816 & 0.055324469 & 0.000314821 & 0.000017417 \\
Euro & 3930000000000 & 14111 & 278506130 & 0.815343090 & 0.000349021 & 0.000284572 \\
Japan 100 yen & 49000000000 & 9150 & 5355191 & 0.015677638 & 0.000170238 & 0.000002669 \\
\hline Total & 4825000000000 & & 341581517 & 1 & 0.000334539 \\
\hline
\end{tabular}

two first columns show numbers of iterations in 9, 11-fold set of iterations. Three second columns indicate changes of objectives importance weight. In five third columns the value of optimal proportion of each exchange in exchange AP, considering the changes of objectives weights is shown and finally, in last three columns, optimal values of each objective are shown in each iteration.

3.1. Evaluating Pareto Optimal Points Specifics. In order to analyze Pareto optimal points, in this section, considering optimal results of each objective, we examine Pareto optimal point set for obtained results and indicate that all obtained results are considered as Pareto optimal point set. First, lets introduce some vector variables. $X^{j *}$ is optimal vector of model variables in iteration $j$ th (for $j=1,2, \ldots, n$ ) of solution (i.e., vector of optimal solution in iteration $j$ th of solution) and $F^{j *}$ is vector of objectives optimal value in iteration $j$ th (for $j=1,2, \ldots, n$ ) of solution. Also, $W^{j *}$ is vector of objectives importance weight in iteration $j$ th (for $j=1,2, \ldots, n)$ of solution. Table 8 presents a set of obtained optimal points based on WGC method. It also should be mentioned that all optimal values of third column are of variable $C_{\mathrm{AP}}^{-}$and finally, sell policy of AP existent assets is offered for future investment. So the purpose is to maximize the positive values of $-F_{3}$ column. For better understanding, Figure 2 shows Pareto optimal set obtained from solving (P7) along with utopia and nadir points.

One of the most important specifics of Pareto optimal set is that all optimal points are nondominated. Let us define being dominated to make clear the concept of being nondominated:
Definition 6. A solution $x^{i *}$ is said to dominate the other solution $X^{j *}$, if the following conditions are satisfied:

(i) the solution $x^{i *}$ is not worse than $X^{j *}$ in all objectives, or $f_{k}\left(x^{i *}\right) \not f_{k}\left(X^{j *}\right)$ for all $k=1,2, \ldots, K$,

(ii) the solution $x^{i *}$ is strictly better than $X^{j *}$ in at least one objective or $f_{k}\left(x^{i *}\right) \triangleleft f_{k}\left(X^{j *}\right)$ for at least one $k=1,2, \ldots, K$.

We can say about the obtained results in Table 8 that all solutions in each set of iterations is nondominated. For example, consider iterations $j=7$ and $j=8$. The results of these two iterations will be

$$
\begin{gathered}
W^{7 *}=(0.9,0.06,0.04) \\
X^{7 *}=(0,0,0.008756436,0.991243600,0) \\
F^{7 *}=(0.0000287172,0.0003487215,0.0033819825) \\
W^{8 *}=(0.9,0.07,0.03) \\
X^{8 *}=(0,0,0.004811658,0.995188300,0) \\
F^{8 *}=(0.0000283654,0.0003488564,0.0022219703)
\end{gathered}
$$

Considering results of the two above iterations, at risk 0.9 importance weight, and by increasing importance weight of return objective and decreasing investment importance weight of cost objective, by considering vectors $X^{7 *}$ and $X^{8 *}$, there is any proportion for dollar, pound and Japan 100 yen 
exchanges in optimal AP and proportion of frank (Euro) exchange is decreasing (increasing) in each set of iterations.

What is implied from values of vectors $F^{7 *}$ and $F^{8 *}$ is that risk objective has improved 0.0000003518 unit and the third objective offers assets selling policy to decrease investment initial cost objective, so that this normalized income in each two iterations will be 0.0033819825 unit and 0.0022219703 unit, respectively. In other words, the extent of income, resulting of selling the assets, has become worse. Also, the results indicate that return value in these two iterations has improved 0.0000001349 unit. In this case, it is said that risk objective decreases by decrease of selling the assets in each set of iterations and vice versa. So considering Definition 6, solutions of these two iterations are nondominated.

Arrangement manner of Pareto optimal set relative to utopia and nadir points is shown in Figure 2. Pareto optimal set is established between two mentioned points, so that it is more inclined toward utopia point and has the maximum distance from nadir point. Actually, external points of solution space which are close to utopia point and far from nadir point are introduced as Pareto optimal points. This somehow indicates that interobjectives tradeoffs are in a manner that distance between Pareto optimal space and utopia point will be minimized and distance between Pareto optimal space and nadir point will be maximized.

3.2. Making Changes in Value of Norm $p$. Because $p$ value changes are by investor's discretion, now we suppose that investor considers value of norm $p=2$ and $\infty$. We optimized (P7) by software Lingo 11.0 under condition $p=2$, and Table 9 (in The Appendix) shows all results in 99 iterations. According to what was said about $p=1$, under this condition, Pareto optimal space is between utopia and nadir points too and tends to become closer to utopia point (see Figure 3).

Finally, we optimize (P7) under condition $p=\infty$. In this condition, considering (P2) approach, (P7) is a weighted minmax model. So (P7) can be rewritten in the form of (P8) as follows:

(P8): $\min y$

$$
\left.\begin{array}{ll}
\text { s.t. } y \geq w_{1}\left(\begin{array}{r}
-0.0000182639+\left(\begin{array}{r}
0.005978413 x_{1}^{2}+5.0975 E-05 x_{2}^{2}+0.006777075 x_{3}^{2}+2.82209 E-05 x_{4}^{2} \\
+3.47045 E-05 x_{5}^{2}-5.50364 E-06 x_{1} x_{2}+6.66602 E-06 x_{1} x_{3}+4.66114 E-06 x_{1} x_{4} \\
+6.73259 E-06 x_{1} x_{5}+3.12959 E-05 x_{2} x_{3}+2.75018 E-05 x_{2} x_{4}+1.15607 E \\
\left.-05 x_{2} x_{5}+5.39984 E-05 x_{3} x_{4}+3.15243 E-05 x_{3} x_{5}+1.93833 E-05 x_{4} x_{5}\right)
\end{array}\right. \\
-0.0000182639+0.006777075
\end{array}\right) \\
\quad y \geq w_{2}\left(\frac{0.000349021-\left(8.49735 E-05 x_{1}+0.000272112 x_{2}+0.000314821 x_{3}+0.000349021 x_{4}+0.000170238 x_{5}\right)}{0.000349021-0.0000849735}\right)
\end{array}\right)
$$

TABLE 4: Utopia and nadir values related to each one of the objectives.

\begin{tabular}{lcc}
\hline Function & Utopia & Nadir \\
\hline$-F_{1}$ & -0.0000182639 & -0.006777075 \\
$F_{2}$ & 0.00034902100 & 0.0000849730 \\
$-F_{3}$ & 0.29488520000 & -0.212363600 \\
\hline
\end{tabular}

Results of solving (P8), by software Lingo 11.0 in 99 iterations, are shown in Table 10 (in the Appendix). Also, Figure 4 shows Pareto optimal set obtained from solving this model.

Considering results obtained from values changes of norm $p$ it can be added that, except nadir point and iterations $j=11,22,33,44$, and 55 (from results of norm $p=\infty$ ), asset
TABLE 5: Results obtained for each objective considering norms of $p=1,2$, and $\infty$ and by assumption $w_{1}=w_{2}=w_{3}$.

\begin{tabular}{lccc}
\hline Objective & $p=1$ & $p=2$ & $p=\infty$ \\
\hline $\operatorname{Min}\left(F_{1}\right)$ & $\mathbf{0 . 0 0 0 3 7 1 1 1 6}$ & 0.001022573 & 0.001388164 \\
$\operatorname{Max}\left(F_{2}\right)$ & $\mathbf{0 . 0 0 0 3 4 1 3 0 7}$ & 0.000297773 & 0.000295503 \\
$\operatorname{Max}\left(-F_{3}\right)$ & 0.067135173 & 0.172916129 & $\mathbf{0 . 1 9 2 0 7 4 2 6 2}$ \\
\hline
\end{tabular}

sell policy will be offered in other results obtained from three examined states.

3.3. Results Evaluation. The most important criterion for examining obtained results is results conformity level with investor's proposed goals. As mentioned before, considering 
TABLE 6: Information obtained of WGC method results, with assumption $p=1,2$, and $\infty$.

\begin{tabular}{lcccc}
\hline Objective function & $F_{1}^{*}$ & $F_{2}^{*}$ & $-F_{3}^{*}$ & Income \\
\hline Objective name & Risk & Rate of return & & \\
\hline$p=1$ & & & 0.141152048 & - \\
Mean & 0.000385422 & 0.000275693 & 0.000806933 & - \\
Min & 0.000028221 & 0.000170333 & 0.294885220 & - \\
Max & 0.006777075 & 0.000349021 & & -161748217 \\
\hline$p=2$ & & & 0.001455988 & - \\
Mean & 0.000610893 & 0.000284013 & 0.281424452 & - \\
Min & 0.000028248 & 0.000172807 & & - \\
Max & 0.002308977 & 0.000348946 & & \\
\hline$p=\infty$ & & & 0.179850336 & $-0.002756123^{*}$ \\
Mean & 0.000789979 & 0.000281186 & 0.000094981 & $-0.000255917^{* *}$ \\
Min & 0.000027132 & 0.000172041 & 0.286319160 & $-0.007842553^{* * *}$ \\
Max & 0.003797903 & 0.000348978 & & \\
\hline
\end{tabular}

Notes: ${ }^{*}$ Mean of cost value obtained (disregard its negative mark).

${ }^{* *}$ Minimum of cost value obtained (disregard its negative mark).

*** Maximum of cost value obtained (disregard its negative mark).

TABLE 7: Summary of Table 6 information.

\begin{tabular}{lccc}
\hline Objective & $p=1$ & $p=2$ & $p=\infty$ \\
\hline Min Risk & 0.000028221 & 0.000028248 & $\mathbf{0 . 0 0 0 0 2 7 1 3 2}$ \\
Max Rate of & $\mathbf{0 . 0 0 0 3 4 9 0 2 1}$ & 0.000348946 & 0.000348978 \\
Return & & 0.281424452 & 0.286319160 \\
Max Income & $\mathbf{0 . 2 9 4 8 8 5 2 2 0}$ & - & $\mathbf{0 . 0 0 0 2 5 5 9 1 7}$ \\
Min Cost & - & &
\end{tabular}

Iran foreign exchange investment policy, investor considers less concentration on US dollar. For example, the results of Table 8 indicate that in each 11-fold set of iterations, by having $w_{1}$ constant and increasing $w_{2}$ and decreasing $w_{3}$, we see decrease of dollar and Japan 100 yen exchanges proportion and increase of Euro exchange proportion in each set of iterations, so that proportion of these exchanges is often zero. Also there is no guarantee for investment on pound exchange. It can be said about frank exchange that there is the first increase and then decrease trends in each set of iterations.

Finally, Tables 8, 9, and 10 indicate that the average of the most exchange proportion in AP belongs to the Euro exchange followed by the Japan 100 yen, frank, dollar, and pound exchanges, respectively. So, considering all results obtained with assumption $p=1,2$, and $\infty$, investor obtains his/her first goal.

Figures 5, 6, and 7 show arrangement of Pareto optimal of all results of $p=1,2$, and $\infty$ norms, between two utopia and nadir points in three different bidimensional graphs. Figure 5 shows tradeoffs between two first and third objectives. As it is seen in this graph, increase of investment risk objective results in increase of income objective obtained from assets sell and vice versa, decrease of obtained income value is along with decrease of investment risk value. Also Tables 8, 9, and 10 show these changes in each 11 -fold set of two $F_{1}$ and $-F_{3}$ columns results.

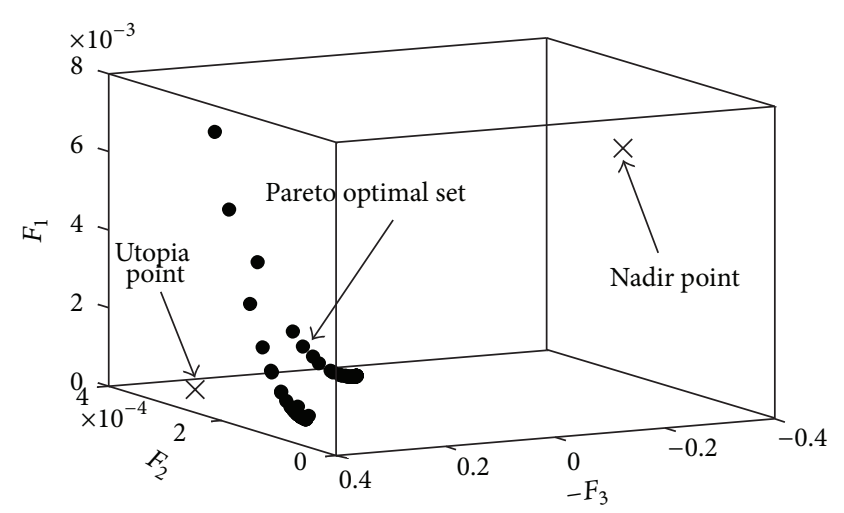

FIGURE 2: Pareto optimal set obtained from solving (P7) with assumption $p=1$.

Figure 6 shows tradeoffs between two second and third objectives. The objective is increase of investment return value and increase of income value obtained from assets sell. Results correctness can be seen in Figure 6, too.

Also, tradeoffs between two first and second objectives can be examined in Figure 7. Because the purpose is decrease of first objective and increase of second objective, so, this graph indicates that we will expect increase (or decrease) of investment return value by increase (or decrease) of investment risk value.

Now, suppose that investor makes no difference between objectives and wants analyst to reexamine the results for different norms of $p=1,2$, and $\infty$, considering the equality of objectives importance. So by assumption $w_{1}=w_{2}=w_{3}$ and $w_{1}+w_{2}+w_{3}=1$, the objectives results will be according to Table 5.

Complete specifications related to Table 5 information are inserted in iteration $j=100$ of Tables 8, 9, and 10. As it is clear in Table 5, third objective offers assets sell policy by assumption $w_{1}=w_{2}=w_{3}$. On the other hand, under 


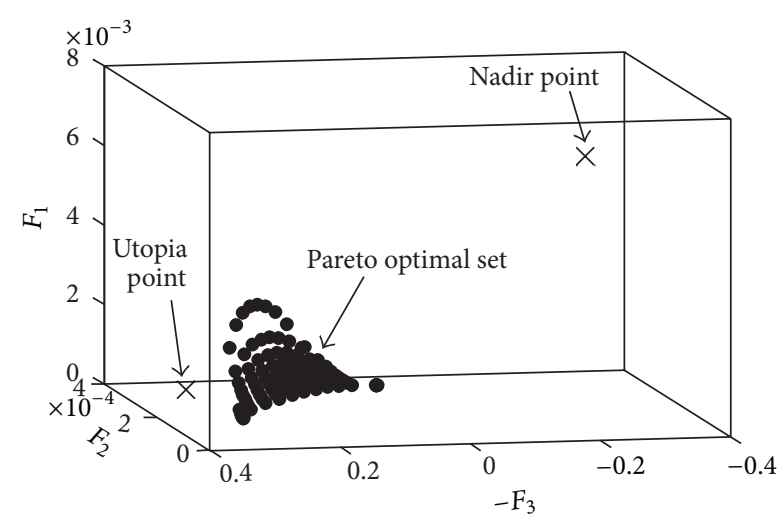

Figure 3: Pareto optimal set obtained from solving (P7) with assumption $p=2$.

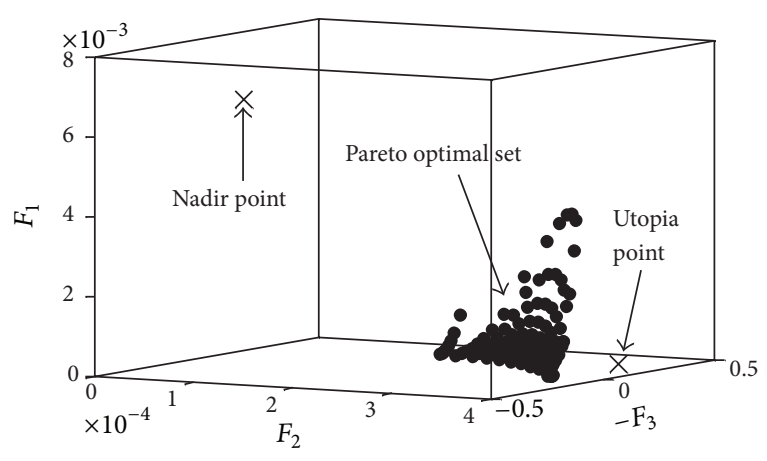

FIgURE 4: Pareto optimal set obtained from solving (P7) with assumption $p=\infty$.

this objective, minimum risk value and maximum investment return value are related to solution obtained in norm $p=$ 1 and maximum income value obtained from assets sell is related to solution obtained in norm $p=\infty$. These values have been bolded in Table 5 .

In here, we consider assessment objectives on the basis of mean, minimum, and maximum value indices in order to assess results of WGC method in three different approaches with assumption $p=1,2$, and $\infty$.

Third objective function optimal values in Table 6 are of both income and cost kind, so that the objective is to increase income and to decrease cost. Generally, results of Table 6 can present different options of case selection to investor for final decision making.

Table 7, which summarizes important information of Table 6, indicates that minimum risk value of exchange AP investment is in $p=\infty$ and iteration $j=11$. Also maximum rate of expected return of investment is in norm $p=1$ and in one of two of the last iteration of each set of solution. And maximum value of income obtained from assets sell can be expected in norm $p=1$ and in iterations $j=93$ or $j=94$. And finally, minimum cost value of new assets buy for AP can be considered in norm $p=\infty$ and in iteration $=55$. These values have been bolded in Table 7 .

Considering Table 6 and mean values of objectives results, we can have another assessment, so that in general, if

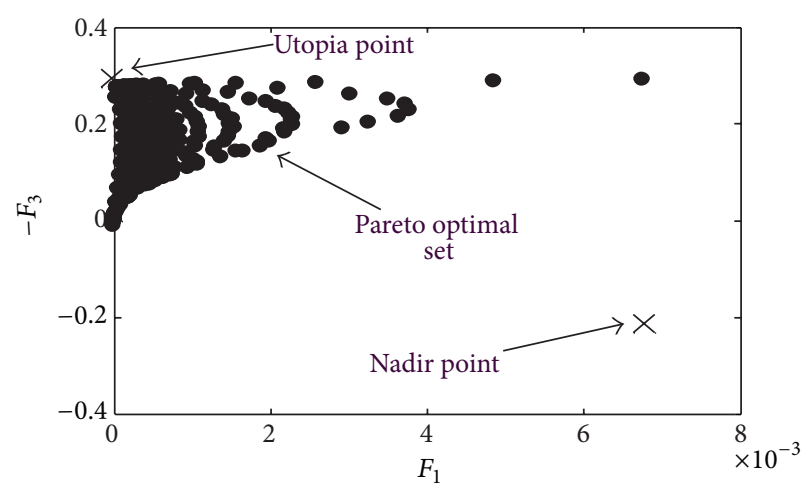

Figure 5: Pareto optimal set arrangement, considering two first and third objectives.

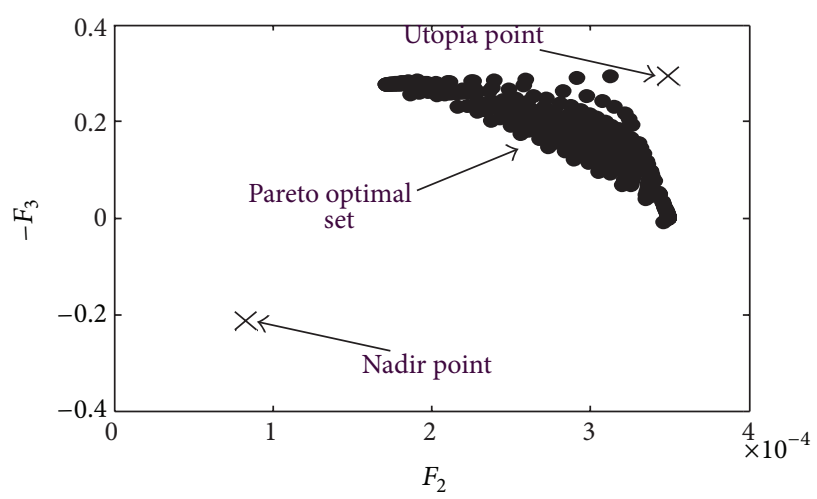

Figure 6: Pareto optimal set arrangement, considering two second and third objectives.

investor gives priority to risk objective he/she will be offered to use obtained results in norm $p=1$. If objective of return is given priority, using norm $p=2$ is offered and if the first priority is given to investment cost objective (by adopting two synchronic policies of buying and selling assets), the results of norm $p=\infty$ will be offered.

Considering the results shown in Figures 2, 3, and 4, it can be seen that that increase of $p$-norm increases effectiveness degree of the WGC model for finding more number of solutions in Pareto frontier of the triobjective problem. So that increasing $p$-norm, we can better track down the optimal solutions in Pareto frontier and diversity of the obtained results can help investor to make a better decision.

3.4. Risk Acceptance Levels and Computing VaR of Investment. Considering obtained results, we now suppose that investor selects risk as his/her main objective. So in this case, investor decides which level of obtained values will be chosen for final selection. By considering importance weights of objectives, we say the following.

(i) In interval $0.1 \leq w_{1} \leq 0.3$, risk acceptance level is low and investor in case of selecting is not a risky person. 


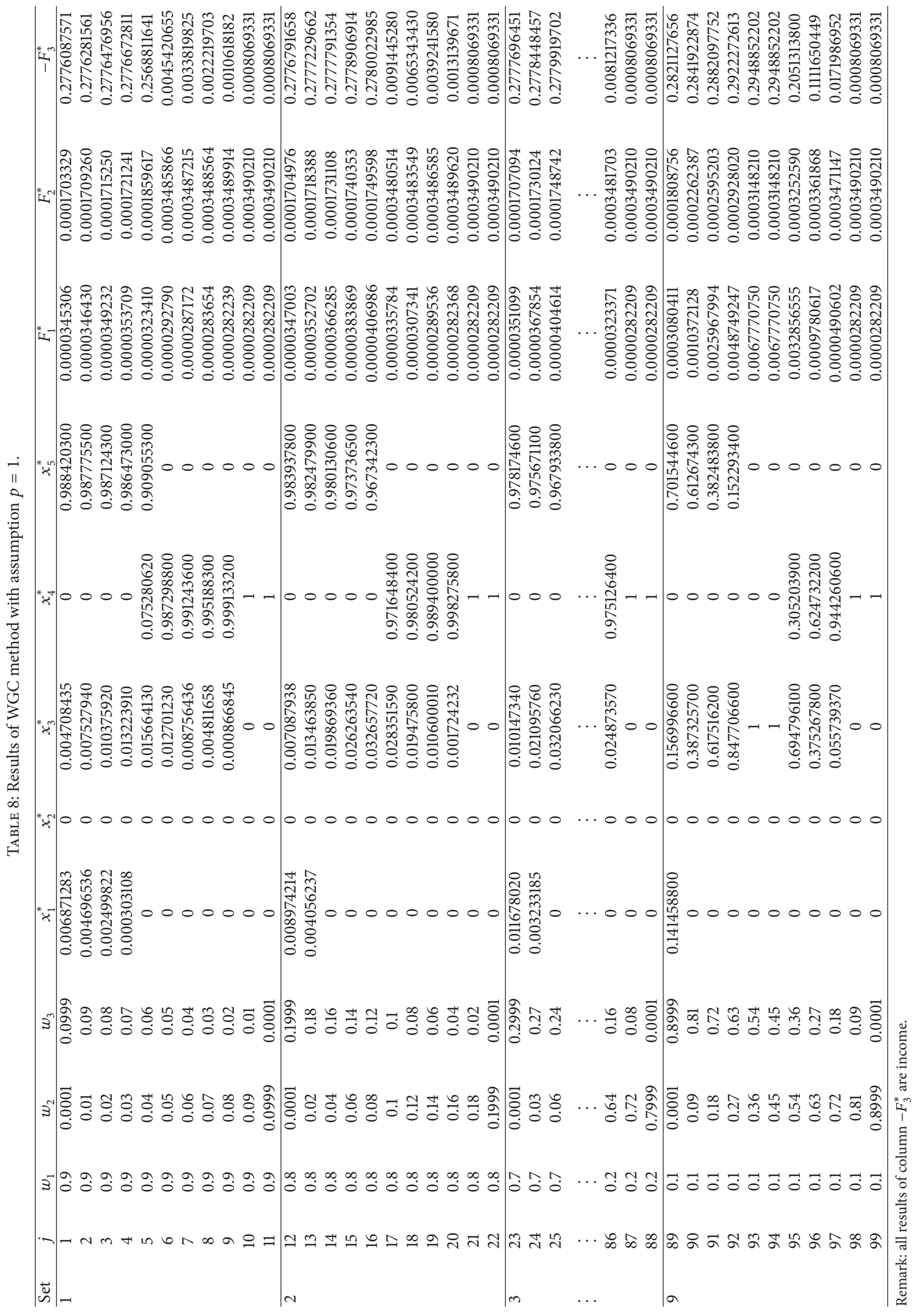




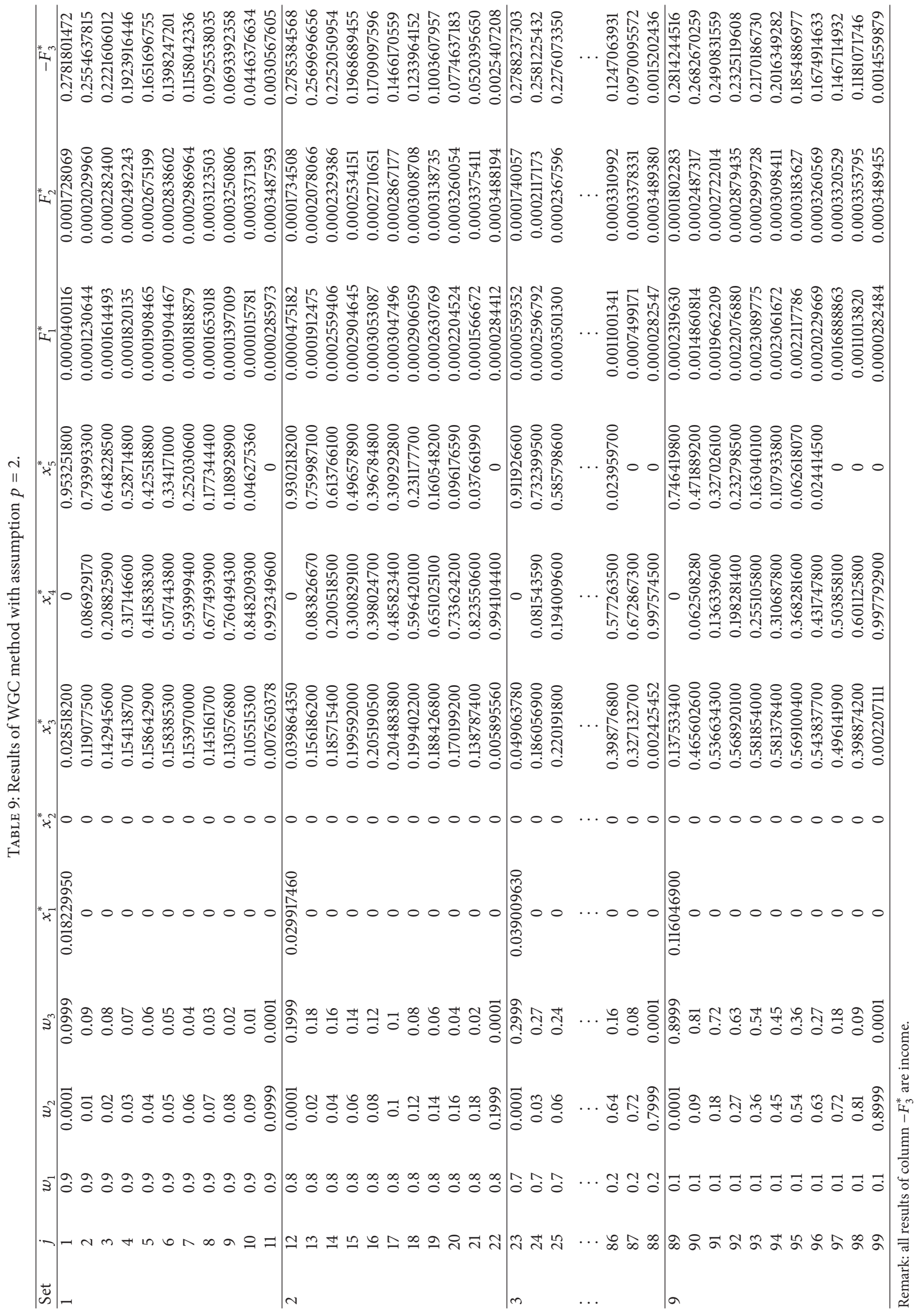




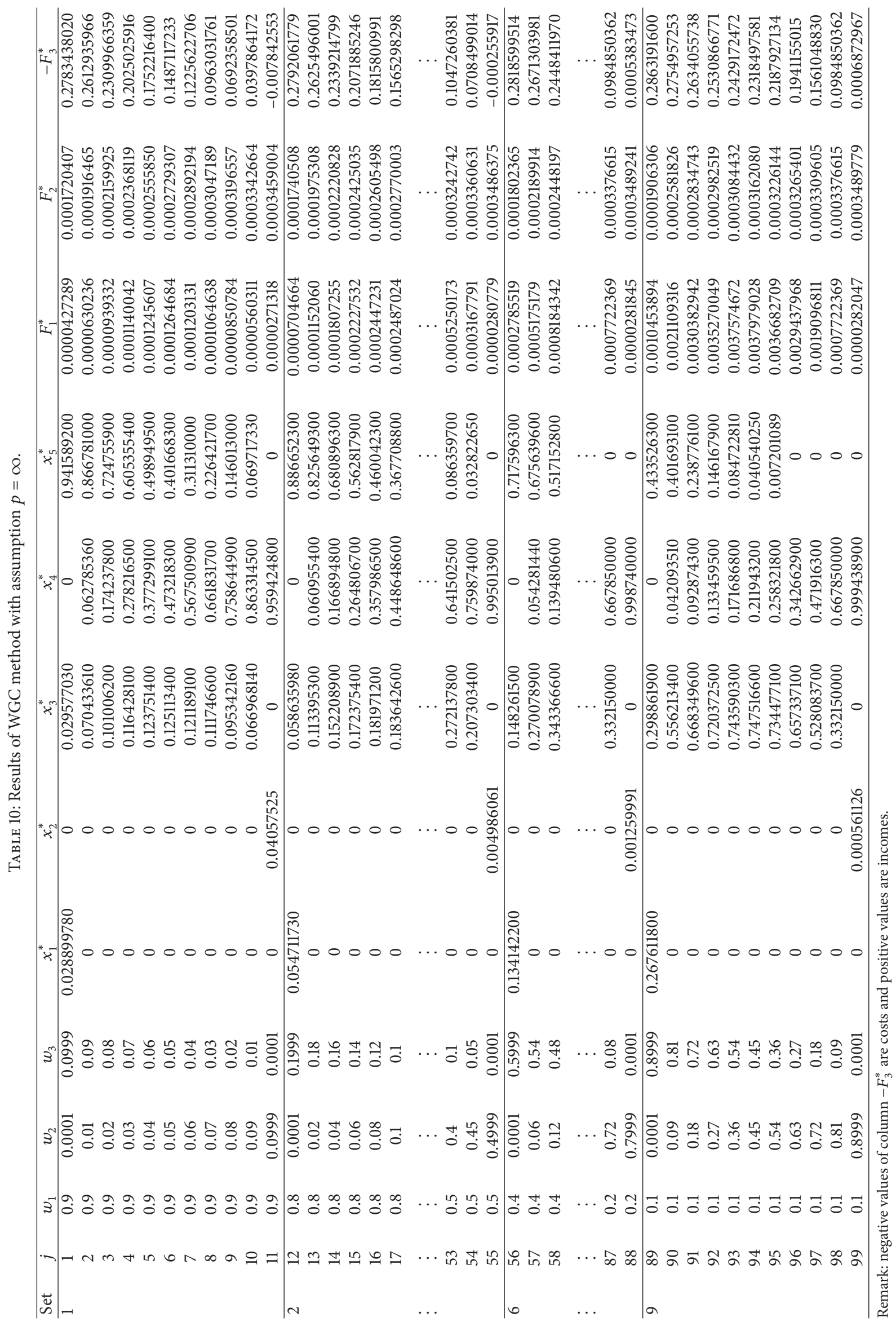




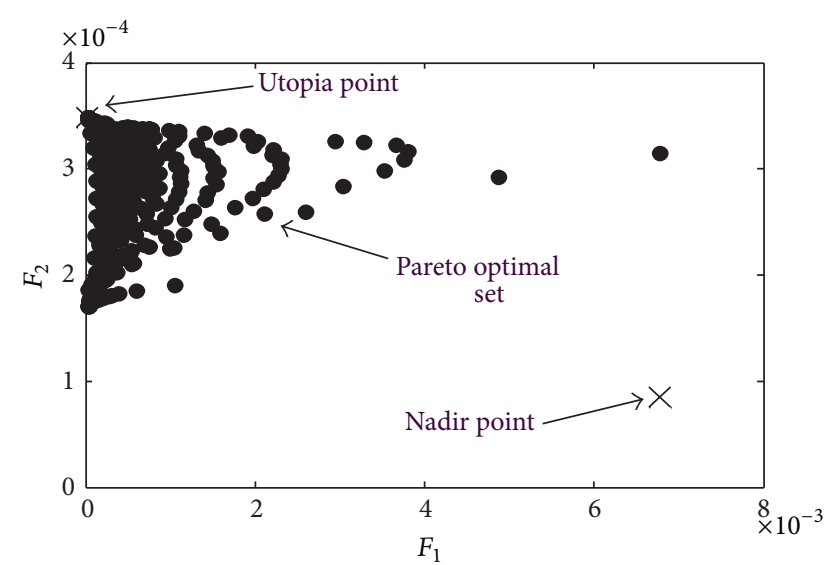

FIGURE 7: Pareto optimal set arrangement, considering two first and second objectives.

(ii) In interval $0.4 \leq w_{1} \leq 0.6$, risk acceptance level is mean and investor in case of selecting is a rather cautious person.

(iii) In interval $0.7 \leq w_{1} \leq 0.9$, risk acceptance level is high and investor in case of selecting is a risky person.

Now let us suppose that, considering Table 10 results, investor selects iteration $j=94$ as his/her optimal solution. Because of thinking important of risk objective, he/she asks analyst about VaR of exchange AP for one-year future term by 250 working days. For this, vectors $X^{94 *}$ and $F^{94 *}$ are as follows:

$$
\begin{aligned}
X^{94 *} & =(0,0,0.747516600,0.211943200,0.040540250), \\
F^{94 *} & =(0.0037979028,0.0003162080,0.2318497581) .
\end{aligned}
$$

By considering Table 3 and (17), and (18) and vector $F^{94 *}$, we have $\operatorname{VaR}_{\mathrm{AP}}(T=250$ days $)=3773773512628.62$ Rials, so that maximum loss during future 250 days and in confidence level of 95\% will not exceed 3773773512628.62 Rials.

\section{Conclusions}

In the beginning of this paper, by defining risk, we indicated specifics of an AP. As mentioned before, an AP is a portfolio that investor, considering market conditions and examining experiences and making balance in assets two by two overlapping, selects assets for investment. It is also said that AP optimization would usually be repeated for a finance term with limited time horizon. Then, we proposed a triobjective model for synchronic optimization of investment risk and return and initial cost on the basis of Markowitz meanvariance model and indicated our motivations for offering this model. Then results obtained from these interobjectives tradeoffs were analyzed for an AP including five major exchanges present in Iran Melli bank investment portfolio. The WGC method (with assumption $p=1,2$, and $\infty$ ) was used to present results of interobjectives tradeoffs.
Then trade-off manner of obtained results under norms $p=1,2$, and $\infty$ were examined on the basis of three bidimensional graphs. It was also seen that third objective offered income obtained from asset sell policy to investor, on the basis of objectives importance weight equality assumption. And finally, the best value of each objective was identified and examined on the basis of results of all three different norms of $p$.

Then risk acceptance different levels were indicated for obtained results and for one of the levels; considering the concept of the VaR method, we computed VaR of investment during a limited time horizon 250 days. After examining obtained results, it was seen that except nadir point and iterations $j=11,22,33,44$, and 55 of Table 10 which offer new asset buying policy, all obtained results offered AP asset selling policy in three examined norms. Also, it is important about the case study results that in three examined norms, in comparison with other exchanges, US dollar exchange proportion was rather the fewest exchange proportion in Iran Melli bank exchange AP in all norms $p=1,2$, and $\infty$. So these results could be considered as a proper trend for decision making of Iran exchange investment policy based on more concentration on other exchanges and less concentration on exchanges like US dollar.

In this paper, a proposal model was introduced, considering investment initial cost objective (by two asset selling or buying policy). Of our proposal model, advantages were to adopt synchronic policy of AP assets selling or buying and consistency of the proposal model with investor goals. Also because there were a lot of numbers of existent assets in understudy AP, proposal model adopted asset selling policy in all iterations but some iteration. Adopting asset selling or buying policy by the model would be sensitive to the number of AP existent assets.

\section{Appendix}

See Tables 8, 9, and 10 .

\section{Conflict of Interests}

The author declares that there is no conflict of interests regarding the publication of this paper.

\section{References}

[1] H. M. Markowitz, "Portfolio selection," The Journal of Finance, vol. 7, no. 1, pp. 77-91, 1952.

[2] S. Benati and R. Rizzi, "A mixed integer linear programming formulation of the optimal mean/value-at-risk portfolio problem," European Journal of Operational Research, vol. 176, no. 1, pp. 423-434, 2007.

[3] A. Prekopa, Stochastic Programming, Kluwer Academic, London, UK, 1995.

[4] R. E. Steuer, Y. Qi, and M. Hirschberger, "Multiple objectives in portfolio selection," Journal of Financial Decision Making, vol. 1, no. 1, pp. 5-20, 2005.

[5] A. D. Roy, "Safety first and the holding of assets," Econometrica, vol. 20, no. 3, pp. 431-449, 1952. 
[6] W. Sharpe, "Capital asset prices: a theory of market equilibrium under conditions of risk," The Journal of Finance, vol. 19, no. 3, pp. 425-442, 1964.

[7] M. Vafaei Jahan and M.-R. Akbarzadeh-T, "External optimization vs. learning automata: strategies for spin selection in portfolio selection problems," Applied Soft Computing, vol. 12, no. 10, pp. 3276-3284, 2012.

[8] M. Amiri, M. Ekhtiari, and M. Yazdani, "Nadir compromise programming: a model for optimization of multi-objective portfolio problem," Expert Systems with Applications, vol. 38, no. 6, pp. 7222-7226, 2011.

[9] W. Zhang, Y. Zhang, X. Yang, and W. Xu, "A class of on-line portfolio selection algorithms based on linear learning," Applied Mathematics and Computation, vol. 218, no. 24, pp. 11832-11841, 2012.

[10] X. Li, B. Shou, and Z. Qin, "An expected regret minimization portfolio selection model," European Journal of Operational Research, vol. 218, no. 2, pp. 484-492, 2012.

[11] K. Tolikas, A. Koulakiotis, and R. A. Brown, "Extreme risk and value-at-risk in the German stock market," The European Journal of Finance, vol. 13, no. 4, pp. 373-395, 2007.

[12] S. S. Hildreth, The Dictionary of Investment Terms, Dearbon Financial, Chicago, Ill, USA, 1989.

[13] S. Arnone, A. Loraschi, and A. Tettamanzi, "A genetic approach to portfolio selection," Neural Network World, vol. 3, no. 6, pp. 597-604, 1993.

[14] G. Vedarajan, L. C. Chan, and D. E. Goldberg, "Investment portfolio optimization using genetic algorithms," in Late Breaking Papers at the Genetic Programming Conference, J. R. Koza, Ed., pp. 255-263, Stanford University, Stanford, Calif, USA, 1997.

[15] W. Briec, K. Kerstens, and O. Jokung, "Mean-variance-skewness portfolio performance gauging: a general shortage function and dual approach," Management Science, vol. 53, no. 1, pp. 135-149, 2007.

[16] H. P. Sharma, D. Ghosh, and D. K. Sharma, "Credit union portfolio management: an application of goal interval programming," Academy of Banking Studies Journal, vol. 6, no. 1-2, pp. 39-60, 2007.

[17] V. Chankong and Y. Y. Haimes, Multiobjectiva Decision Making Theory and Methodology, Elsevier Science, New York, NY, USA, 1983.

[18] A. Messac and A. Ismail-Yahaya, "Required relationship between objective function and pareto frontier orders: practical implications," The American Institute of Aeronautics and Astronautics Journal, vol. 39, no. 11, pp. 2168-2174, 2001.

[19] K. Miettinen, Nonlinear Multi-Objective Optimization, Kluwer Academic, Boston, Mass, USA, 1999.

[20] P. L. Yu, "A class of solutions for group decision problems," Management Science, vol. 19, no. 8, pp. 936-946, 1973.

[21] M. Zeleny, Multiple Criteria Decision Making, Mc Graw Hill, New York, NY, USA, 1982.

[22] Y. L. Chen, "Weighted-norm approach for multiobjective VAr planning," IEE Proceedings, vol. 145, no. 4, pp. 369-374, 1998.

[23] K. Dowd, D. Blake, and A. Cairns, "Long-term value at risk," The Journal of Risk Finance, vol. 5, no. 2, pp. 52-57, 2004.

[24] K. Dowd, Measuring Market Risk, John Wiley \& Sons, New York, NY, USA, 2nd edition, 2005. 


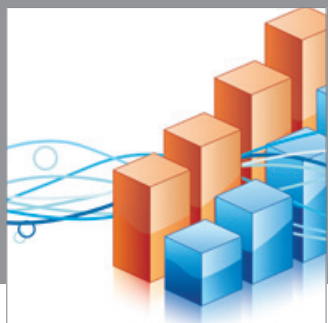

Advances in

Operations Research

mansans

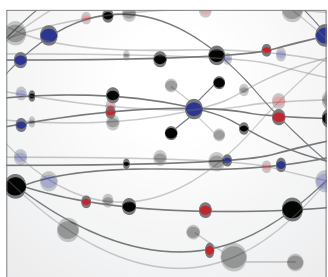

The Scientific World Journal
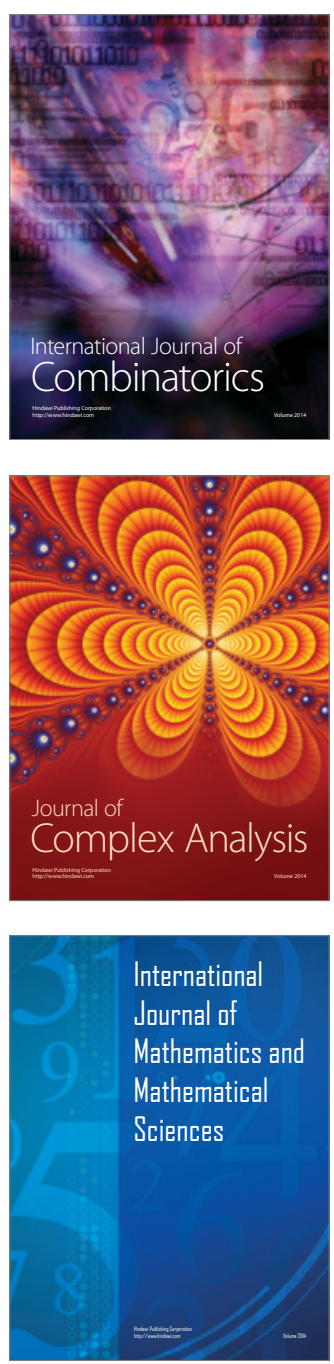
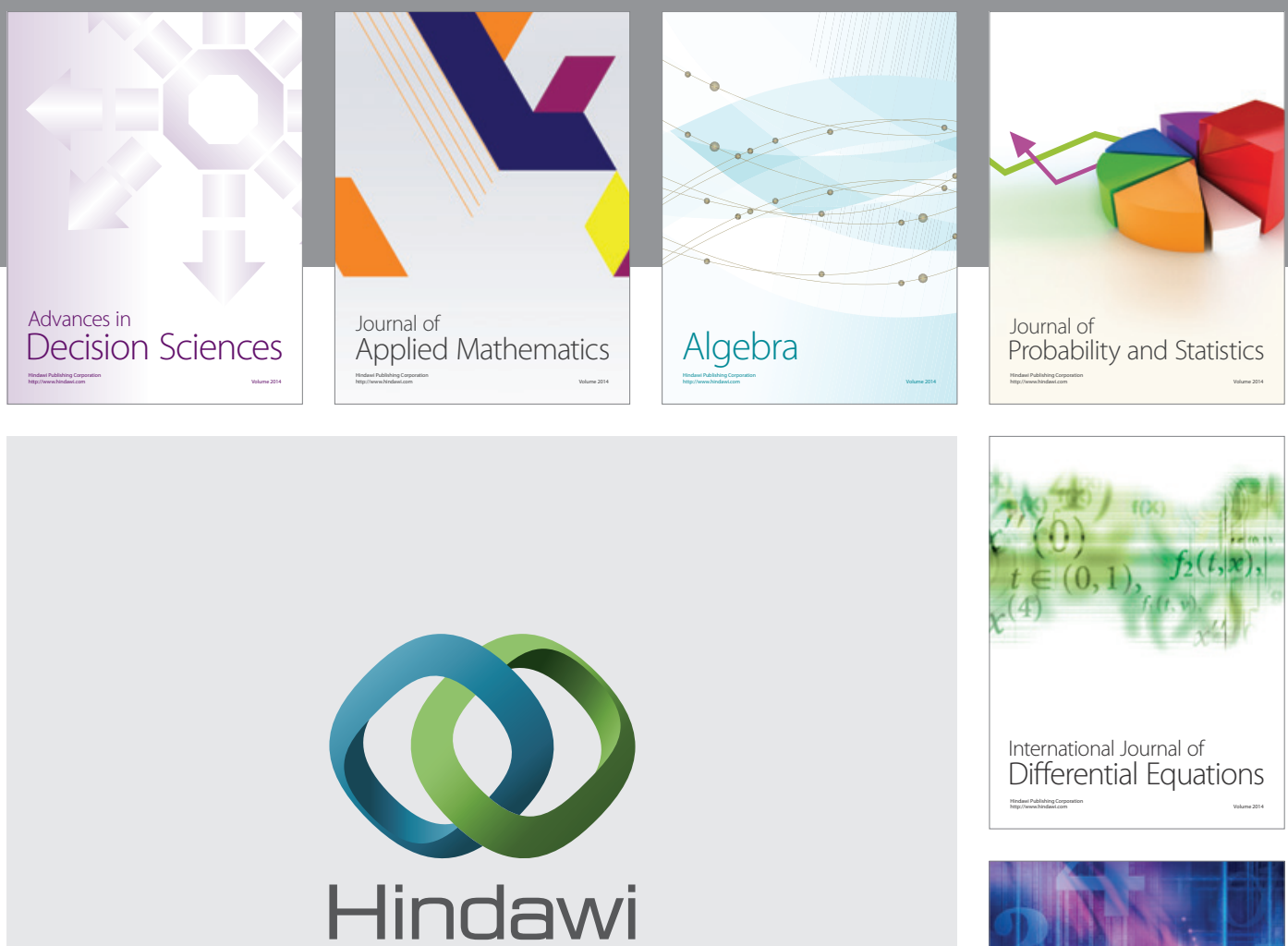

Submit your manuscripts at http://www.hindawi.com
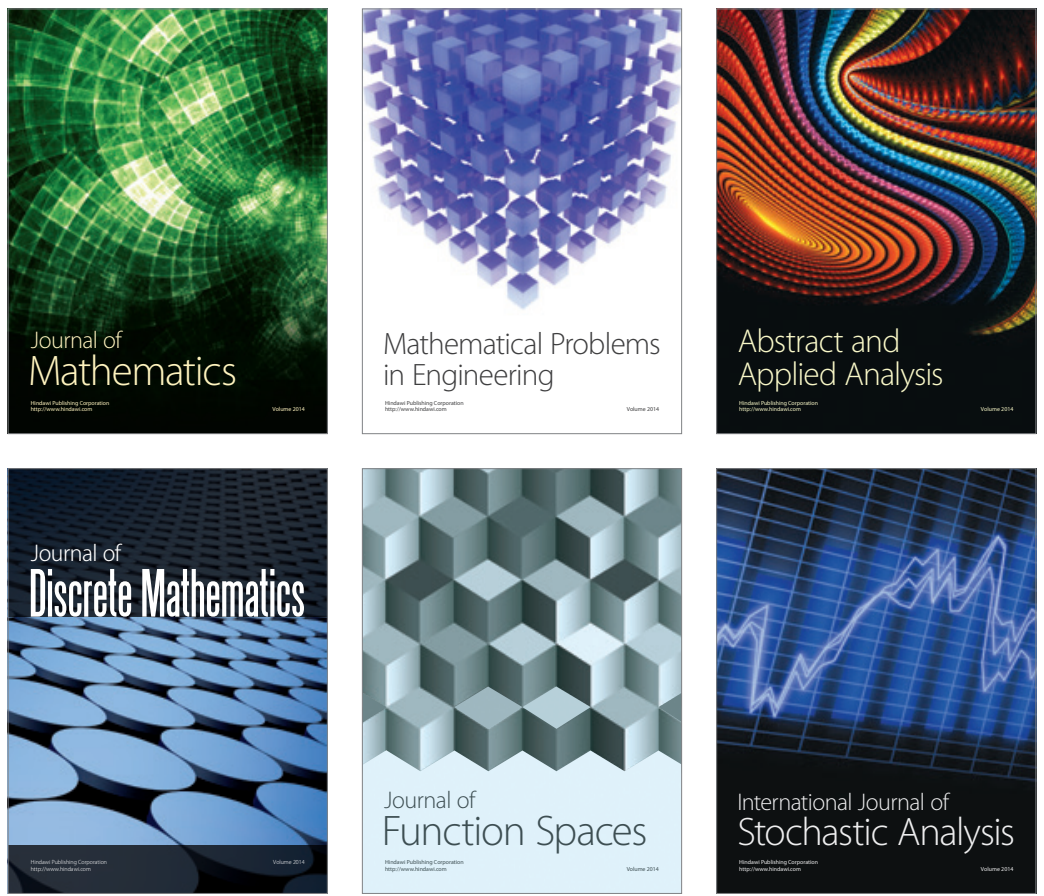

Journal of

Function Spaces

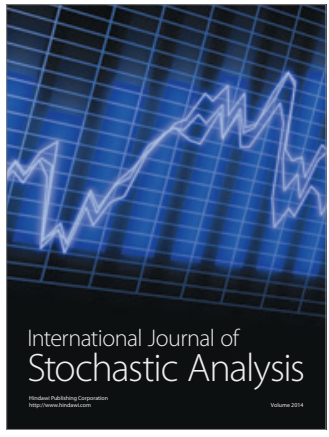

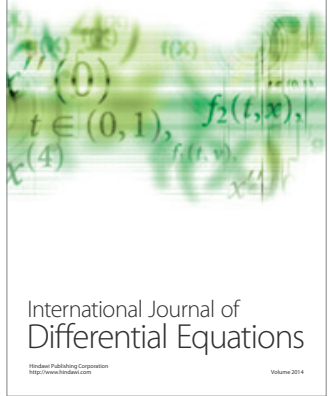
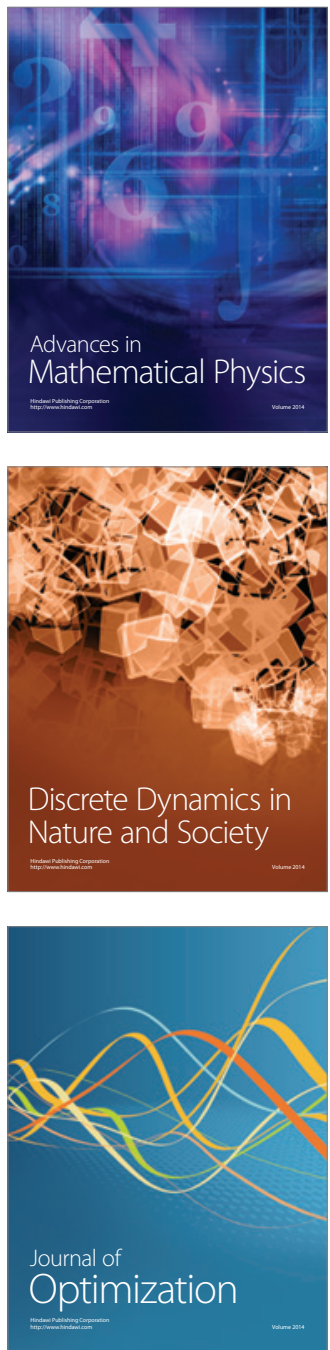